\title{
Heterologous Expression, Purification, and Biochemical Characterization of $\alpha$-Humulene Synthase from Zingiber zerumbet Smith
}

\author{
Semra Alemdar ${ }^{1} \cdot$ Steffen Hartwig $^{1} \cdot$ Thore Frister $^{1} \cdot$ Jan Christoph König $^{1} \cdot$ Thomas \\ Scheper $^{1}$ - Sascha Beutel ${ }^{1}$
}

\begin{abstract}
The $\alpha$-humulene synthase from Zingiber zerumbet Smith was expressed as a polyhistidine-tagged protein in an E. coli BL21(DE3) strain. Induction time and inductor (isopropyl- $\beta$-D-thiogalactopyranoside) concentration were optimized. The enzyme was successfully purified directly from cell lysate by NTA affinity column chromatography and careful selection of coordinated metal ion and imidazole elution conditions. Bioactivity assays were conducted with the natural substrate farnesyl diphosphate (FDP) in a two-phase system with in situ extraction of products. The conversion of FDP to $\alpha$-humulene $(\sim 94.5 \%)$ and $\beta$ caryophyllene $(\sim 5.5 \%)$ could be monitored by gas chromatography-flame ionization detection (GC-FID). Optimal $\mathrm{pH}$ and temperature as well as kinetic parameters $K_{\mathrm{M}}$ and $k_{\text {cat }}$ were determined using a discontinuous kinetic assay.
\end{abstract}

Keywords Terpene synthase $\cdot$ Sesquiterpene $\cdot$ Humulene $\cdot$ Recombinant expression $\cdot$ Purification · Enzyme activity

\section{Introduction}

Natural products continue to be the most important source of lead compounds for the pharmaceutical industry since the past century [1]. Many natural products have been successfully developed for the clinical use to treat human diseases in a wide range of therapeutic areas [2]. Although synthetic chemistry has also produced many new bioactive substances and combinatorial techniques have considerably expanded the

Sascha Beutel

beutel@iftc.uni-hannover.de

Institute of Technical Chemistry, Gottfried Wilhelm Leibniz University of Hannover, Callinstr. 5, 30167 Hannover, Germany 
number of compounds available for tests, natural products and their derivatives represent over $50 \%$ of drugs in clinical use [3].

With over 30,000 characterized substances, terpenes are the largest and most structurally diverse class of natural products. Terpenes are widely distributed in nature occurring in plants, bacteria, fungi, and marine organisms. However, most of the isolated and identified terpene structures are of herbal origin. As primary metabolites, they are essential for plant survival, having functions in, e.g., respiratory system, in photosynthesis, and in regulation of plant growth [4-7]. A majority of terpenes are compounds of the secondary metabolism, playing an important role, e.g., in defense and protection mechanisms [8] or in plant volatile communication [9].

Despite their extensive application in industrial sector as flavors and fragrances in food as well as in perfumery and cosmetic products, many terpenes have biological activities and are used for the treatment of human diseases. The worldwide sales of terpene-based pharmaceuticals in 2002 were approximately US\$12 billion [10]. More and more terpenes have been discovered as effective compounds in human disease therapy and prevention, presumably leading to an increasingly important role of terpenoids as medical drugs.

The sesquiterpenoid zerumbone is a highly potential pharmaceutical agent. It was first isolated from the rhizome of tropical wild shampoo ginger (Zingiber zerumbet Smith) [11]. Presently, zerumbone has been extensively studied for its effectiveness in a broad range of biological activities including antimicrobial [12], antioxidant [13], antidiabetic [14], antitumor [15], anti-inflammatory [16], antiangiogenic [17] and antiallergic properties [18].

The biosynthesis of zerumbone in $Z$. zerumbet Smith from the sesquiterpene precursor farnesyl diphosphate (FDP) is analogous to other known plant sesquiterpene ketones [19, 20] (Fig. 1). In the initial step, the reaction of FDP is catalyzed by $\alpha$-humulene synthase (HUM) giving $\alpha$-humulene as the major product (95\%) and $\beta$-caryophyllene as the minor product (5\%) [11]. In a subsequent reaction by $\alpha$-humulene- 8 -hydroxylase, $\alpha$-humulene is converted to 8 -hydroxy- $\alpha$-humulene [21] which is finally oxidized by the dehydrogenase zerumbone synthase to yield zerumbone [22].

$\alpha$-Humulene synthase is a key enzyme in zerumbone biosynthesis. Although $\alpha$-humulene is a common sesquiterpene widely distributed in plants, the synthase from $Z$. zerumbet Smith is the only known sesquiterpene synthase catalyzing the formation of $\alpha$-humulene as major product.

In this work, we describe the heterologous expression and purification of $\alpha$-humulene synthase from Z. zerumbet Smith in E. coli. Although the sesquiterpene synthase was

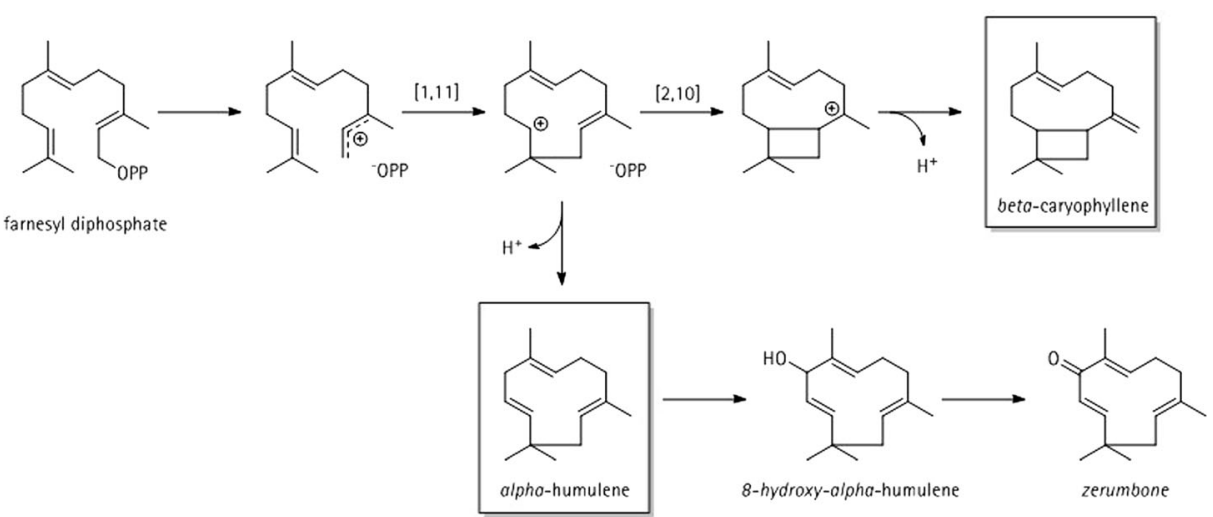

Fig. 1 Proposed mechanism of zerumbone biosynthesis in Z. zerumbet Smith. Products of the catalyzed reaction of $\alpha$-humulene synthase are highlighted 
published previously [11], no characterization of key enzymatic properties was described to date. Herein we present a characterization of recombinant $\alpha$-humulene synthase in terms of temperature and $\mathrm{pH}$ optimum, $\mathrm{p} I$, and the first ever determined enzyme kinetic data.

\section{Materials and Methods}

\section{Cloning of Expression Construct}

The complementary DNA (cDNA) sequence GenBank: AB247331 [11] was carefully codonoptimized for expression in E. coli K12 derivative strains using a guided-random approach [23]. The optimized sequence (1684 bp) was ordered as two individual double stranded DNA fragments of $684 \mathrm{bp}$ and $1000 \mathrm{bp}$ length using the GeneArtC Strings ${ }^{\mathrm{TM}}$ service (Life Technologies, USA). For fast and seamless cloning, the proprietary GeneArt $\subset$ Seamless cloning $\&$ assembly system (Life Technologies, USA) was used, which exploits overlapping fragments created by PCR to ligate seamless constructs without restriction enzyme digestion. Primers were designed to create a 15-bp overlap of the inserts and vectors after amplification (Table 1).

To yield long and error-free PCR products, the circular vector pET16b (Life Technologies, USA) as well as both synthetic DNA strings were amplified using Q5 ${ }^{\circledR}$ High-Fidelity DNA Polymerase (NEB, USA). Typical PCR reactions consisted of $10 \mu \mathrm{l} 5 \times$ Q5 HF buffer, $1 \mu \mathrm{l}$ dNTP mix (10 mM each), $2.5 \mu \mathrm{l}$ respective forward and reverse primer (10 $\mu \mathrm{M}$ each), $1 \mu \mathrm{l}$ cDNA template, and $0.5 \mu \mathrm{l}$ Q5 DNA polymerase in a total volume of $50 \mu \mathrm{l}\left(\operatorname{add} \mathrm{H}_{2} \mathrm{O}\right)$. PCR reactions were performed at $98{ }^{\circ} \mathrm{C}$ for $10 \mathrm{~s}$ for initial denaturation, 15 cycles at $98{ }^{\circ} \mathrm{C}$ for $10 \mathrm{~s}$, $72-62{ }^{\circ} \mathrm{C}$ for $30 \mathrm{~s}$ (Touchdown PCR annealing step), and $72{ }^{\circ} \mathrm{C}$ for $1 \mathrm{~min}$. Following the initial touchdown PCR cycles, additional 20 cycles consisting of denaturation at $98{ }^{\circ} \mathrm{C}$ for $10 \mathrm{~s}$, annealing at $62{ }^{\circ} \mathrm{C}$ for $30 \mathrm{~s}$, elongation at $72{ }^{\circ} \mathrm{C}$ for $1 \mathrm{~min}$, and a final elongation at $72{ }^{\circ} \mathrm{C}$ for $10 \mathrm{~min}$ were conducted. Elongation time was raised up to $3 \mathrm{~min}$ and $20 \mathrm{~s}$ for PCR of the vector fragment. PCR conditions and annealing temperatures were adapted depending on primers and templates used in the reaction. PCR reactions using plasmid DNA as template were digested with DpnI (NEB, USA) for $1 \mathrm{~h}$ at $37{ }^{\circ} \mathrm{C}$ to lower background after transformation. Fragment sizes were verified by analytical agarose gels, and the products were purified using QIAquick PCR Purification Kit (QIAGEN GmbH, Germany). Assembly reactions were conducted following manufacturer recommendations, and $8 \mu \mathrm{l}$ of the fused construct were chemically transformed in competent $E$. coli TOP10 cells (Life Technologies, USA). Plasmid DNA of positive clones was purified, sequenced, and transformed into E. coli BL21(DE3) cells (Merck Millipore, Germany) for expression studies.

Table 1 Primers designed for use in seamless assembly reaction of the optimized hum gene

\begin{tabular}{ll}
\hline Description & Primer sequence $\left(5^{\prime}-3^{\prime}\right)$ \\
\hline pET16b_Vector_FWD & CATATGCTCGAGGATCCG \\
pET16b_Vector_REV & ACGACCTTCGATATGGCC \\
Hum_opt_Str1_FWD & CATATCGAAGGTCGTGAGCGACAATCGATGGCGCT \\
Hum_opt_Str1_REV & GGAACACAGTCGACCGCCTGCGGTTCCCACCGCTC \\
Hum_opt_Str2_FWD & GTGGGAACCGCAGGCGGTCGACTGTGTTCCCGAAT \\
Hum_opt_Str2_REV & ATCCTCGAGCATATGTTAGATCAAGAAAGATTCCA \\
\hline
\end{tabular}




\section{Expression of Sesquiterpene Synthase in $E$. coli}

The expression of terpene synthase gene in E. coli was carried out in TB (terrific broth) medium (12 $\mathrm{g} \cdot \mathrm{l}^{-1}$ tryptone, $24 \mathrm{~g} \cdot \mathrm{l}^{-1}$ yeast extract, $4 \mathrm{ml} \cdot \mathrm{l}^{-1}$ glycerol, $10 \mathrm{ml} \cdot \mathrm{l}^{-1}$ potassium phosphate buffer) and SB (super broth) medium ( $32 \mathrm{~g} \cdot 1^{-1}$ tryptone, $24 \mathrm{~g} \cdot 1^{-1}$ yeast extract, $5 \mathrm{~g}$. $\left.1^{-1} \mathrm{NaCl}, 5 \mathrm{ml} \cdot 1^{-1} \mathrm{NaOH}(1 \mathrm{~N})\right)$. Precultures were set up in $25 \mathrm{ml}$ of LB-Miller medium supplemented with carbenicillin $\left(100 \mu \mathrm{g} \cdot \mathrm{ml}^{-1}\right)$. The medium was inoculated with glycerol stocks of cells and incubated overnight at $37{ }^{\circ} \mathrm{C}$ and $150 \mathrm{rpm}$ in an orbital shaker. Main cultures in TB or SB medium containing the same concentration of antibiotics were inoculated with preculture to give an initial optical density of $\mathrm{OD}_{600} 0.1 \mathrm{rel}$. AU and grown under the same conditions as above to specify absorbance values at $600 \mathrm{~nm}$. Gene expression was induced by adding isopropyl- $\beta$-D-thiogalactopyranoside (IPTG) at a specific final concentration, and growth was continued at $20^{\circ} \mathrm{C}$ and $150 \mathrm{rpm}$ for $24 \mathrm{~h}$ post induction. Culture samples were normalized according to their optical density at $600 \mathrm{~nm}$ to monitor recombinant protein production by SDS-PAGE. After centrifugation $\left(4000 \times \mathrm{g}, 4{ }^{\circ} \mathrm{C}, 15 \mathrm{~min}\right)$, cell pellets were resuspended in extraction buffer (50 $\mathrm{mM}$ MOPS pH 7.0, $5 \mathrm{mM} \mathrm{MgCl}_{2}, 5 \mathrm{mM} \mathrm{DTT,} 10 \%(v / v)$ glycerol) and sonicated during $6 \times 15 \mathrm{~s}$ time intervals $(0.6 \mathrm{~s}$ cycle, $100 \%$ amplitude) while the cell suspension was kept on ice to prevent heating-up. Cell extracts were centrifuged $\left(14,000 \times g, 4{ }^{\circ} \mathrm{C}, 45 \mathrm{~min}\right)$, and the supernatant containing the total soluble protein extract was collected. Insoluble protein pellets were suspended in lysis buffer $(100 \mathrm{mM}$ potassium phosphate $\mathrm{pH}$ 7.0, $10 \mathrm{mM}$ sodium metabisulfite, $10 \mathrm{mM} \beta$-mercaptoethanol, $10 \mathrm{mM}$ ascorbic acid, $6 \mathrm{M}$ urea) and solubilized by shaking at $30^{\circ} \mathrm{C}$ for $1 \mathrm{~h}$. Samples were directly applied in SDS-PAGE analysis (5\% stacking gel, $10 \%$ separation gel). Gels were stained by colloidal coomassie staining. PageRuler Prestained Protein Ladder \#26616 and Pierce Unstained Protein MW Marker \#26610 (both Thermo Scientific, USA) were used as molecular weight markers.

\section{Bioreactor Cultivation}

Bioreactor cultivations were carried out at $20{ }^{\circ} \mathrm{C}$ in a 2-L bioreactor (Biostat B, B. Braun Biotech, Melsungen, Germany). SB medium was used as production medium in 1.81 working volume. Foam production was controlled by the addition of antifoam. The $\mathrm{pH}$ value was maintained at $\mathrm{pH} 7$ by adding $1 \mathrm{M}$ sodium hydroxide solution. The concentration of dissolved oxygen was kept constantly at $20 \%$ air saturation by adjusting the stirrer speed (0-1700 rpm) at an aeration rate of $1 \mathrm{vvm}$.

The starter culture was prepared by inoculating a glycerol stock into $25 \mathrm{ml} \mathrm{LB}$ medium and subsequently incubating at $37^{\circ} \mathrm{C}, 150 \mathrm{rpm}$ for $10 \mathrm{~h}$. The culture was diluted up to an $\mathrm{OD}_{600}$ of $0.1 \mathrm{rel}$. AU in $100 \mathrm{ml} \mathrm{SB}$ medium and grown for further $10 \mathrm{~h}$ at $37^{\circ} \mathrm{C}, 150 \mathrm{rpm}$. The reactor was inoculated with preculture to give an initial $\mathrm{OD}_{600}$ of 0.1 rel. AU. Cultivations in a bioreactor were carried out at $37^{\circ} \mathrm{C}$. After IPTG addition, temperature was lowered to $20^{\circ} \mathrm{C}$. Cells were sampled at different times to monitor biomass and recombinant protein production.

\section{Purification of Recombinant Sesquiterpene Synthase}

Biomass was harvested after $24 \mathrm{~h}$ post induction by centrifugation $\left(4000 \times \mathrm{g}, 4{ }^{\circ} \mathrm{C}, 15 \mathrm{~min}\right)$ and resuspended in IMAC binding buffer (50 mM MOPS pH 7.5, $500 \mathrm{mM} \mathrm{NaCl}, 10 \mathrm{mM} \mathrm{MgCl}_{2}$, $50 \mathrm{mM}$ imidazole, $10 \%(\mathrm{v} / \mathrm{v})$ glycerol) to give a concentration of $100 \mathrm{mg}$ wet cell-mass per milliliter. The cell suspension was sonicated during $10 \times 15 \mathrm{~s}$ time intervals $(0.6 \mathrm{~s}$ cycle, $100 \%$ 
amplitude) on ice. After centrifugation $\left(4000 \times g, 4{ }^{\circ} \mathrm{C}, 60 \mathrm{~min}\right)$, the supernatant was filtered using $0.2-\mu \mathrm{m}$ syringe filters. The recombinant sesquiterpene synthase was purified from protein extract using an HiTrap ${ }^{\mathrm{TM}}$ IMAC FF $5 \mathrm{ml}$ affinity column (GE Healthcare, USA), decorated with specific divalent cations $\left(\mathrm{Cu}^{2+}, \mathrm{Ni}^{2+}, \mathrm{Co}^{2+}, \mathrm{Zn}^{2+}\right)$ on a BioLogic DuoFlow FPLC system (Bio-Rad Laboratories Inc., USA). Preparation of columns with different cations was performed following manufacturer's instructions. After binding to the column matrix, unbound protein was washed off with binding buffer. The subsequent elution of the target protein was carried out with IMAC elution buffer (50 mM MOPS pH 7.5, $500 \mathrm{mM} \mathrm{NaCl}, 10 \mathrm{mM} \mathrm{MgCl}$, $500 \mathrm{mM}$ imidazole, $10 \%(v / v)$ glycerol). Eluted fractions were concentrated using a Vivaspin 20 ultrafiltration unit with a molecular weight cut-off (MWCO) of $10 \mathrm{kDa}$ (Sartorius-Stedim Biotech, Germany), followed by a buffer exchange to a storage buffer (50 mM MOPS pH 7.0, $15 \mathrm{mM} \mathrm{MgCl}_{2}, 5 \mathrm{mM}$ sodium ascorbate, $5 \mathrm{mM} \mathrm{DTT}, 10 \%(v / v)$ glycerol $)$ in three ultrafiltration steps. Aliquots of $100 \mu \mathrm{l}$ enzyme solution were stored at $-20^{\circ} \mathrm{C}$.

Homogeneity of the recombinant enzyme product was analyzed by SDS-PAGE and Western blots after purification. Enzyme purity was determined by densitometry of colloidal coomassie-stained SDS-PAGE gels. Western blots were performed after semi-dry plotting on PVDF membrane, using 6x-His epitope tag mouse antibody \#MA1-21315 (Thermo Scientific, USA) as primary and goat anti-mouse HRP conjugate \#401215 (Calbiochem, USA) as secondary antibody. Blots were stained using 3,3',5,5'-Tetramethylbenzidine (TMB) as substrate. Quantification was done by measuring adsorption at $280 \mathrm{~nm}$ (theoretical MW $64.5 \mathrm{kDa}$, extinction coefficient 90,190 $\mathrm{M}^{-1} \mathrm{~cm}^{-1}$ ) with Nano-Drop $1000 \mathrm{UV}$-vis spectrophotometer (Thermo Scientific, USA).

\section{Biotransformation Assay and GC-FID Analysis of Sesquiterpenes}

A single-vial assay method for bioactivity testing of sesquiterpene synthases was adapted. Bioactivity assay of the purified sesquiterpene synthase was conducted using $1.6 \mu \mathrm{g}$ of protein in a total reaction volume of $500 \mu$ activity buffer (50 mM MOPS pH 7.0, $15 \mathrm{mM} \mathrm{MgCl}_{2}$, $5 \mathrm{mM}$ sodium ascorbate, $5 \mathrm{mM}$ DTT) containing $30 \mu \mathrm{M}$ FDP tris-ammonium salt (Mobitec, Germany). Assay mixture was overlaid with $200 \mu$ iso-octane and incubated for $15 \mathrm{~min}$ at $38{ }^{\circ} \mathrm{C}$. Terpene products were extracted by vigorous shaking for $30 \mathrm{~s}$. The organic phase was removed after centrifugation and analyzed by GC-FID.

\section{Identification of Enzyme Kinetic Parameters}

Kinetic analysis of the recombinant enzyme was conducted using a discontinuous kinetic assay. Master mixes consisting of activity buffer (50 mM MOPS pH 7.0, $15 \mathrm{mM} \mathrm{MgCl}_{2}$, $5 \mathrm{mM}$ sodium ascorbate, $5 \mathrm{mM} \mathrm{DTT}$ ) and FDP tris-ammonium salt at certain varying concentrations $(1,5,10,20,30,50,80,10 \mu \mathrm{M})$ were prepared for each assay run to yield a total volume of $2.8 \mathrm{ml}$. The reaction was initiated by the addition of $0.05 \mu \mathrm{M}$ (final concentration) recombinant sesquiterpene synthase to a total reaction volume of $2.8 \mathrm{ml}$. The assay mix was immediately splitted into five separate reaction tubes $(500 \mu \mathrm{l}$ reaction volume each), overlaid with $200 \mu$ iso-octane, and incubated in a water bath at $38{ }^{\circ} \mathrm{C}$. The linear reaction was terminated at certain time intervals $(0.5,1,2,3,4 \mathrm{~min})$ by intensive shaking for $30 \mathrm{~s}$. Phases were separated by short centrifugation, and the organic layer was transferred to a GC vial for further GC-FID analysis. The initial reaction slope for each sample was determined by linear regression. Kinetic constants of the recombinant sesquiterpene synthase were 
determined by fitting the data to the Michaelis-Menten model by non-linear regression using GraphPad Prism software (GraphPad Software Inc., USA). Data presented represent the means of at least two determinations.

A calibration curve using commercially available $\alpha$-humulene (Sigma-Aldrich, Germany) was generated for the purpose of quantifying sesquiterpenes. $\alpha$-Humulene standards were made in iso-octane at concentrations of $0.05,0.5,1,2.5,5$, and $10 \mu \mathrm{g} \cdot \mathrm{ml}^{-1}$. Samples were measured by the aforementioned GC-FID method. A calibration curve was generated by plotting the average peak area of each sample against its concentration.

\section{Determination of Optimal Temperature and $\mathrm{pH}$}

Optimal temperature and $\mathrm{pH}$ of the recombinant terpene synthase were determined by the above mentioned discontinuous kinetic assay method at various designed temperatures $(34,36$, $\left.38,40,42,44^{\circ} \mathrm{C}\right)$ and $\mathrm{pH}(\mathrm{pH} 6,6.5,7,7.5,8,8.5,9)$, respectively. Samples were analyzed by GC-FID, and initial reaction slopes were plotted to the temperature or $\mathrm{pH}$. Data presented represent the means of at least two determinations.

\section{Results and Discussion}

\section{Soluble Expression in $E$. coli and Optimization of Expression Conditions}

\section{Induction Time}

A parametric study was conducted to optimize the induction conditions in the production of recombinant $\alpha$-humulene synthase in the overexpressing strain of $E$. coli BL21(DE3) in shakeflask cultures. In the plasmid pET16b::his-FXa-hum, the $\alpha$-humulene synthase gene (hum) is under the control of the lac promoter. IPTG was used to induce the lac promoter for the synthesis of $\alpha$-humulene synthase.

The growth behavior of recombinant E. coli BL21(DE3) cells containing the codonoptimized hum overexpressing plasmid pET16b::his-FXa-hum was investigated. The culture was inoculated to an initial $\mathrm{OD}_{600}$ of $0.1 \mathrm{rel}$. $\mathrm{AU}$ and cultivated at $37{ }^{\circ} \mathrm{C}$ in standard $\mathrm{TB}$ medium. The growth curve is shown in Fig. 2.

The exponential phase was completed within a time course of $12 \mathrm{~h}$ after which the cells entered the stationary phase. Higher cell concentrations may reduce production of recombinant

Fig. 2 Growth curve of $E$. coli BL21(DE3)/pET16b::his-FXa-hum cells at $37^{\circ} \mathrm{C}$ in TB medium

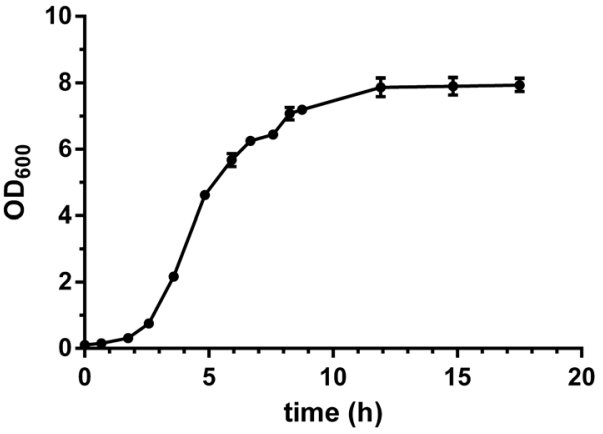


protein, as nutrient limitation may occur. According to Eriksen et al., an increase in solubility of recombinant protein is observed when expression is induced in early-exponential phase [24]. Hence, induction of cells was investigated in lag to mid-exponential phase. In order to determine the time course of induction, five shake-flask fermentations were performed in parallel. Main cultures in TB medium were inoculated to an initial $\mathrm{OD}_{600}$ of $0.1 \mathrm{rel}$. AU and grown at $37^{\circ} \mathrm{C}$ to an $\mathrm{OD}_{600}$ of $0.1,0.5,1.0,3.0$ or 4.0 rel. AU, and then induced with $0.1 \mathrm{mM}$ IPTG (final concentration). After addition of the inducer to the cultivation broth, growth temperature was lowered to $20{ }^{\circ} \mathrm{C}$ to improve protein solubility. Incubation of flasks was continued for $24 \mathrm{~h}$. Samples were taken directly before IPTG addition and at the end of cultivation time after $24 \mathrm{~h}$ to analyze protein production by SDS-PAGE. The amounts of recombinant enzyme produced by varying induction time were determined by gel densitometry after sonication. SDS-PAGE gels of soluble and insoluble cell fractions are shown in Fig. 3a, b.

The highest enzyme yield of $\sim 3.20 \mu \mathrm{g} \cdot \mathrm{mg}^{-1} \mathrm{WCW}$ in cell extracts was found to be attained when expression was induced at an $\mathrm{OD}_{600}$ of 1.0 rel. AU. However, SDS-PAGE analysis of insoluble cell fractions shows an increase in recombinant enzyme production when inducing at lower cell densities. It can be suggested that the recombinant sesquiterpene synthase is produced more actively in cells at an early stage of growth and therefore tends to form inclusion bodies in order to minimize toxic effects for the cells. As it is important to obtain HUM in its soluble form, an $\mathrm{OD}_{600}$ of $1.0 \mathrm{rel}$. AU was determined to be the optimum time point for induction for further experiments.

\section{Inductor Concentration}

After determining the optimal induction time, the effect of the inducer concentration on the efficiency of the induction was examined by using $0.025,0.05,0.1,0.15$, and $0.2 \mathrm{mM}$ IPTG concentrations. Five parallel shake-flask cultivation fermentations were performed in TB medium, and all cultures were inoculated to an initial $\mathrm{OD}_{600}$ of 0.1 rel. AU. All cultures were grown to an $\mathrm{OD}_{600}$ of 1.0 at $37{ }^{\circ} \mathrm{C}$ and subsequently IPTG was added to each culture flask to induce expression. Cultures were incubated at $20^{\circ} \mathrm{C}$ for further $24 \mathrm{~h}$. Again, samples were taken directly before IPTG addition and at the end of cultivation time after $24 \mathrm{~h}$. Cell extracts as well as insoluble cell fractions obtained after sonication were analyzed by SDS-PAGE (Fig. 4a, b).

The protein gels show that an increase in IPTG concentrations resulted in a higher HUM production. Although the amount of recombinant protein produced in the cells steadily increases, most of the protein is found to aggregate in inclusion bodies. An increase of IPTG concentration from 0.1 to $0.2 \mathrm{mM}$ did not result in any significant improvement in soluble protein production. Densitometric analysis of the cell extracts shows that the highest yield of soluble recombinant HUM with $\sim 3.35 \mu \mathrm{g} \cdot \mathrm{mg}^{-1} \mathrm{WCW}$ is obtained when inducing expression with $0.15 \mathrm{mM}$ IPTG.

\section{Medium Optimization}

To ensure sufficient nutrient supply, the cultivation medium was further enhanced by providing threefold concentration of tryptone (SB medium) during the subsequent optimization steps to adapt cultivation process to bioreactor. Densitometric SDS-PAGE analysis of soluble cell extracts and insoluble cell fractions showed a higher recombinant protein production $(\sim 13 \%)$ in SB medium than in TB medium (Fig. 5). Besides, cultivations in SB medium yielded in a higher biomass production. Densitometric analysis showed a soluble/insoluble protein ratio of 40:60\%. 


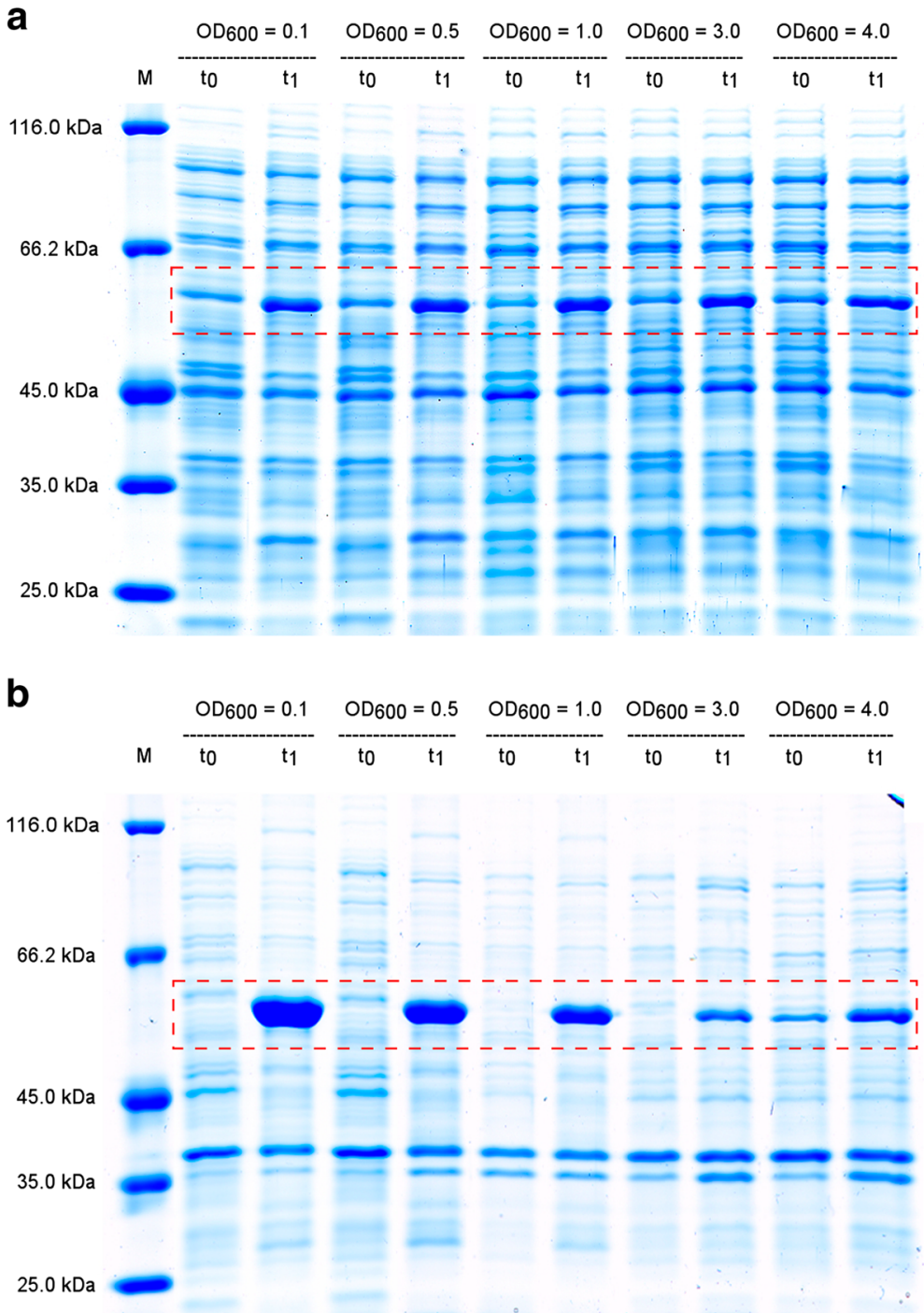

Fig. 3 SDS-PAGE gels of recombinant $\alpha$-humulene synthase production in E. coli BL21(DE3) cells in dependency of induction time point. Gels showing expression of codon-optimized hum gene in both soluble (a) and insoluble (b) fractions. Samples were normalized based on $\mathrm{OD}_{600} . M$ marker, $t_{0}$ sample before induction with IPTG, $t_{1}$ sample $24 \mathrm{~h}$ after induction and expression at $20^{\circ} \mathrm{C}$

\section{Bioreactor Cultivation}

The conditions set up at flask level were scaled up at 21 batch bioreactor scale. When cells reached an optical density of $\mathrm{OD}_{600}=1.0 \mathrm{rel}$. AU (as indicated by the arrow in Fig. 6), HUM production was induced by adding $0.15 \mathrm{mM}$ IPTG to the reactor, and temperature was decreased from 37 to $20^{\circ} \mathrm{C}$.

HUM production increased consistently until $9 \mathrm{~h}$ after induction. Beyond that point, a decrease in HUM concentration was observed. The rapid degradation of HUM indicates 

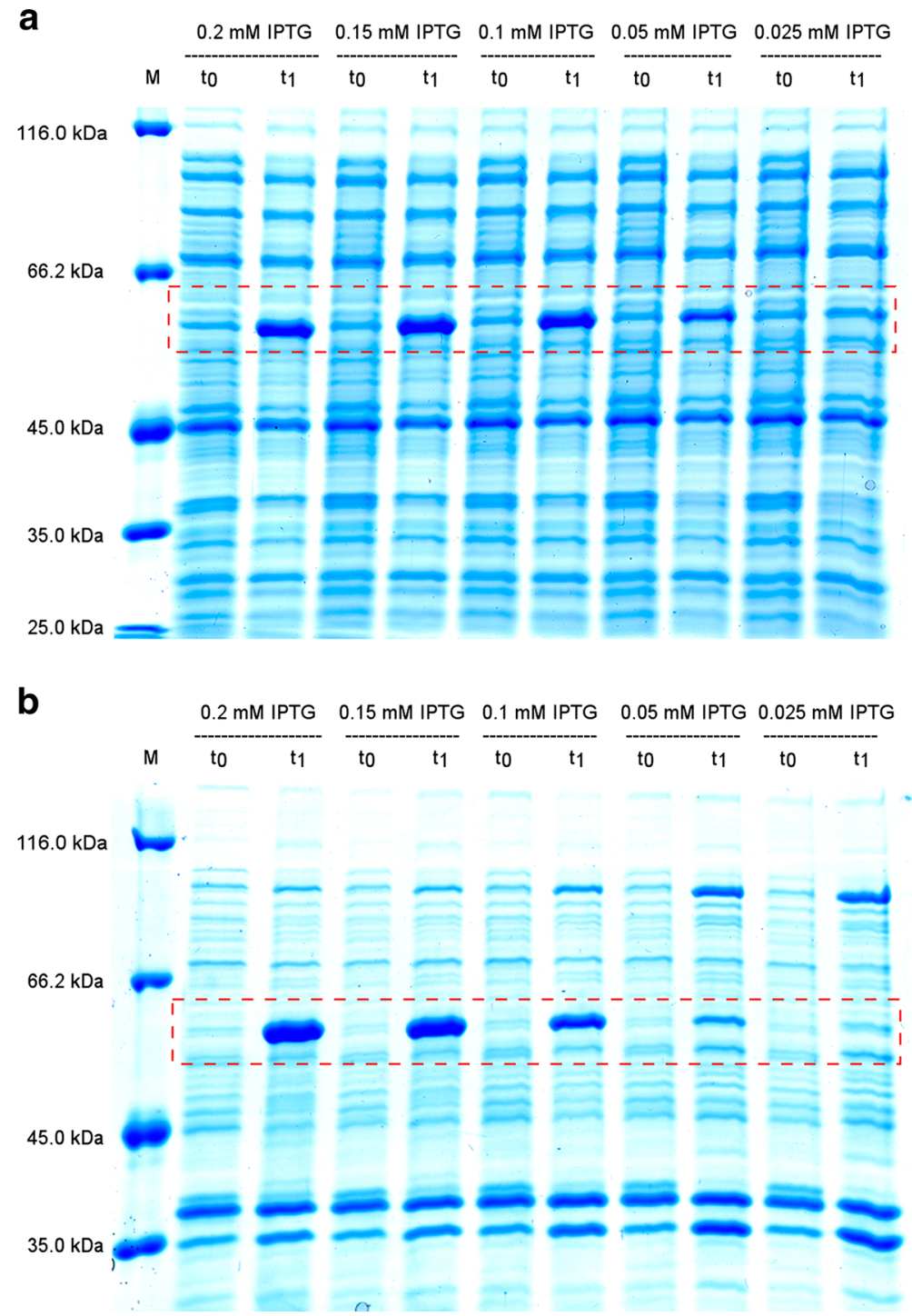

Fig. 4 SDS-PAGE gels of recombinant $\alpha$-humulene synthase production in E. coli BL21(DE3) cells in dependency of inductor concentration. Gels showing expression of codon-optimized hum gene in both soluble (a) and insoluble (b) fractions. Samples were normalized based on $\mathrm{OD}_{600}$. $M$ marker, $t_{0}$ sample before induction with IPTG, $t_{1}$ sample $24 \mathrm{~h}$ after induction and expression at $20^{\circ} \mathrm{C}$

that nutrient deficiency presumably a depletion of one or more essential amino acids occurred. Total consumption of a certain amino acid may lead to changes in metabolic flow, protein synthesis, and possibly also leads to short-time stringent response before the cell induces the set of enzymes for synthesis of this amino acid. Degradation of the recombinant protein provides amino acids for the synthesis of essential proteins. Final HUM production level reached $140 \mathrm{mg} \cdot 1^{-1}$ in comparison to $156 \mathrm{mg} \cdot 1^{-1}$ at the highest point of production. Therefore, cells should be harvested before nutrient deficiency occurs. 




Fig. 5 Comparison of recombinant $\alpha$-humulene synthase production in E. coli BL21(DE3) cells in TB and SB medium. SDS-PAGE gels showing expression of codon-optimized hum gene in both soluble (a) and insoluble (b) fractions. Samples were normalized based on $\mathrm{OD}_{600}$. $M$ marker, $t_{0}$ sample before induction with IPTG, $t_{1}$ sample $24 \mathrm{~h}$ after induction and expression at $20^{\circ} \mathrm{C}$

\section{Purification of Recombinant $\alpha$-Humulene Synthase}

After cell disruption and centrifugation, recombinant $\alpha$-humulene synthase was purified from cell extracts by immobilized metal ion chromatography (IMAC) using NTA ligands. For optimal purification conditions, four different cations, namely $\mathrm{Cu}^{2+}, \mathrm{Ni}^{2+}, \mathrm{Co}^{2+}$, and $\mathrm{Zn}^{2+}$, that coordinated to NTA on matrix surface were analyzed regarding purification efficiency and product

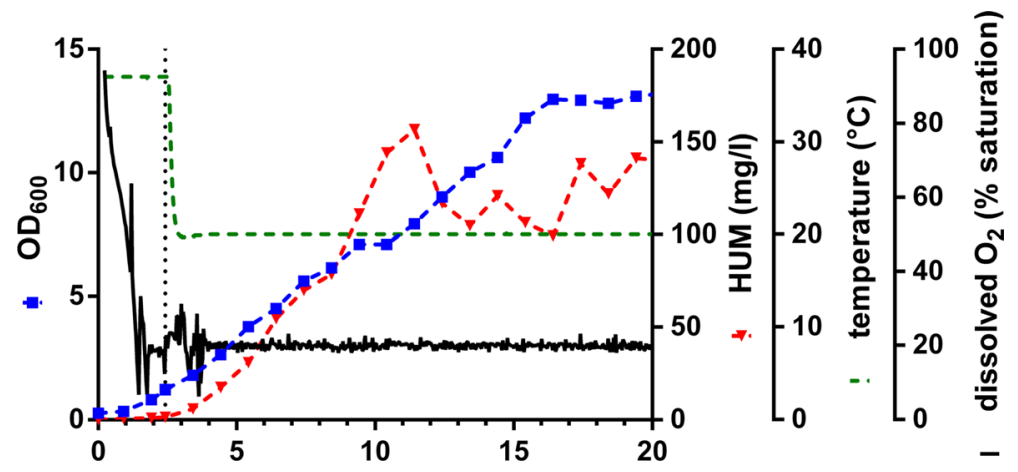

Fig. 6 IPTG induced production of recombinant $\alpha$-humulene synthase during batch cultivation of $E$. coli BL21(DE3)/pET16b::his-FXa-hum. HUM concentrations in the reactor were estimated by gel densitometry. Time point of induction with $0.15 \mathrm{mM}$ IPTG is indicated by a dashed line 
recovery. To reduce non-specific binding of endogenous $E$. coli proteins onto the matrix surface, $10 \mathrm{mM}$ imidazole was added to the binding buffer. After washing off unbound protein, the recombinant enzyme was eluted with $500 \mathrm{mM}$ imidazole in buffer. Eluted fractions containing the protein of interest were pooled, fused, and dialyzed by ultrafiltration with Sartobind ultrafiltration units (MWCO $10 \mathrm{kDa}$ ). Buffer exchange against activity buffer containing $\mathrm{Mg}^{2+}$ ions was performed in three subsequent steps resulting in an imidazole dilution of 1:9000. Fractions containing protein were kept cooled during the whole purification process to prevent protein degradation and inactivation. The purification efficiency using different metal ions was compared by SDS-PAGE analysis with sensitive silver-staining (Fig. 7).

Flow-through fractions showed no unbound HUM leading to the assumption that the histagged recombinant enzyme was bound efficiently to NTA ligands irrespective of the coordinated metal ion. However, eluted fractions show significant differences in purity. Coordinating $\mathrm{Cu}^{2+}$ ions to the NTA ligands resulted in a high non-specific binding of endogenous host cell proteins due to the high affinity of $\mathrm{Cu}^{2+}$ to histidine groups. $\mathrm{Zn}^{2+}$-IMAC showed much less impurities in eluted protein fractions which is consistent with the fact that $\mathrm{Zn}^{2+}$ ions are less affine to histidine groups. However, the recovery rate of $80 \%$ of the protein of interest using $\mathrm{Zn}^{2+}$ ions is the lowest compared to all other metal ions tested. $\mathrm{Ni}^{2+}-$ and $\mathrm{Co}^{2+}$-IMAC seemed to be similar in product purity (60 and $63 \%$ ) and recovery (93 and $95 \%$ ). $\mathrm{As} \mathrm{Co}^{2+}$-IMAC showed the best purity to recovery ratio, further purification experiments were done using $\mathrm{Co}^{2+}$-IMAC.

To enhance product purity, $\mathrm{Co}^{2+}$-IMAC was conducted using an imidazole gradient up to $500 \mathrm{mM}$ imidazole (data not shown). An imidazole concentration of $50 \mathrm{mM}$ was determined to be suitable to remove most of the host cell proteins bound to the matrix. Therefore, purification of the his-tagged synthase was done by a two-step elution, the first step with imidazole concentrations of $50 \mathrm{mM}$ and the second step with $500 \mathrm{mM}$ imidazole to elute the protein of interest (Fig. 8a, b). Enzyme recovery was $\sim 67 \%$, whereas enzyme purity was densitometrically determined to be $>92 \%$.

Western blot was prepared using a rather non-specific anti-his antibody as there is no known specific antibody for the enzyme. Western blot showed that the his-tagged enzyme could be successfully isolated from cell extracts (Fig. 9a). To determine the isoelectric point, a 2D gel electrophoresis was conducted including an isoelectric focusing step in the range of $\mathrm{pH} 3-10$

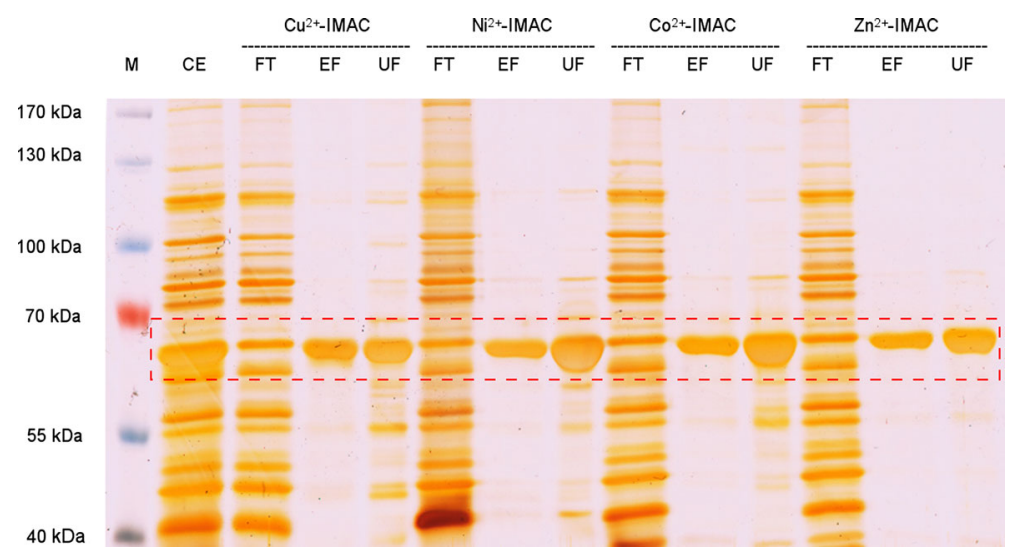

Fig. 7 Metal affinity chromatography using $\mathrm{Cu}^{2+}, \mathrm{Ni}^{2+}, \mathrm{Co}^{2+}$, and $\mathrm{Zn}^{2+} . M$ marker, $C E$ cell extract of $E$. coli BL21(DE3)/pET16b::his-FXa-hum before being loaded on IMAC column, FT flow-through fractions, EF pooled eluted fractions, $U F$ concentrated protein after ultrafiltration 

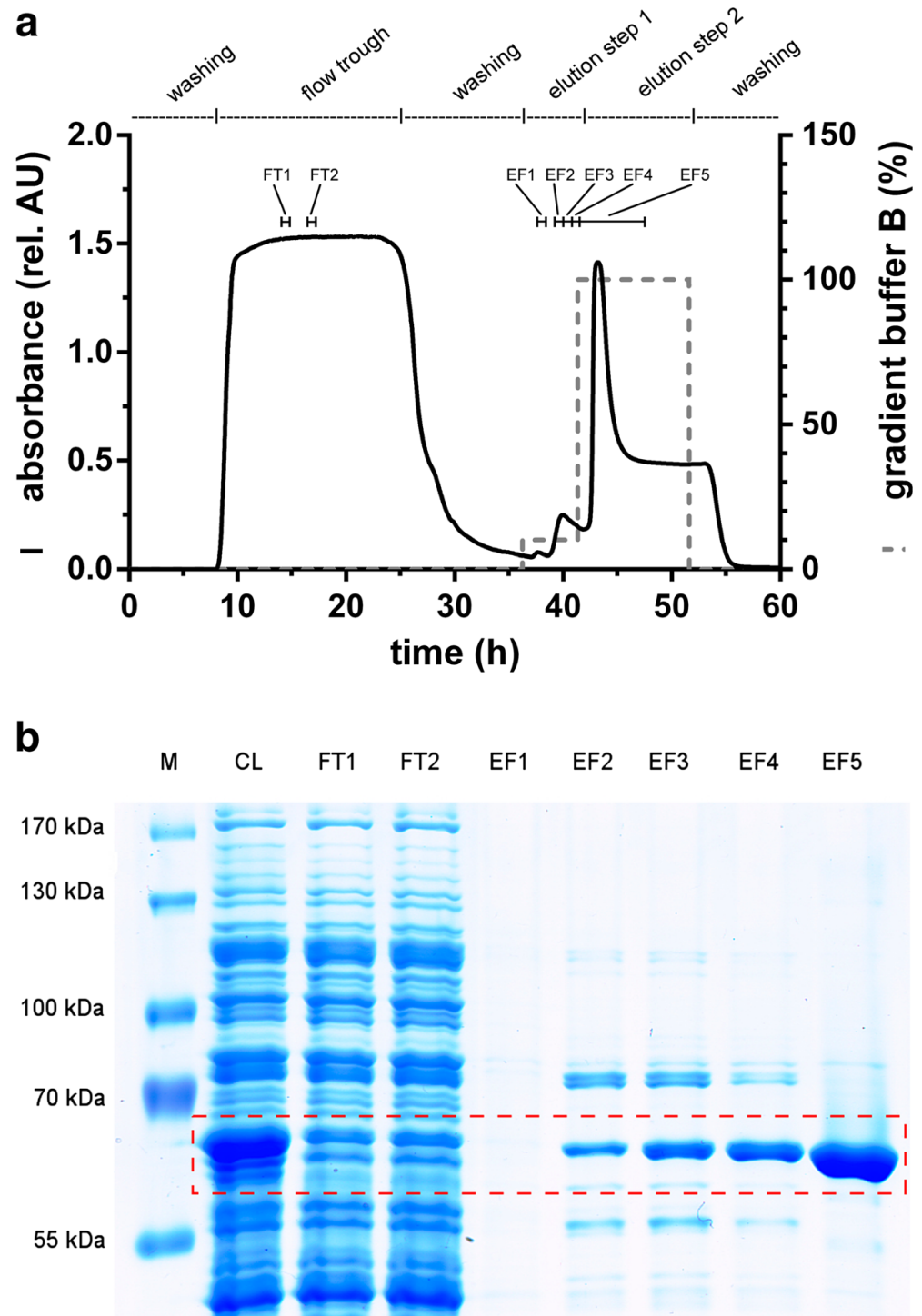

Fig. 8 Metal affinity chromatography of clarified cell lysate using $\mathrm{Co}^{2+}$ (a). Elution was carried out with a two-step elution with imidazole. SDS-PAGE gel (b) shows collected FPLC fractions. $M$ marker, $C L$ cell lysate of E. coli BL21(DE3)/pET16b::his-FXa-hum before being loaded on IMAC column, FT1-2 flow-through fractions, EF1-4 eluted fractions, EF5 pooled and concentrated eluted fraction

(Fig. 9b). The native $\mathrm{p} I$ was determined to be $\sim 5.61$ for the his-tagged protein which nearly matches the calculated $\mathrm{p} I$ of 5.65 and is comparable to other sesquiterpene synthases $[25,26]$.

\section{Bioactivity Assay and Effect of Temperature and pH on Terpene Synthase Activity}

To assess the product spectrum of the recombinant HUM, bioactivity assays with the natural substrate farnesyl diphosphate were performed in a 500- $\mu$ l scale in a two-phase system with an aqueous reaction solution containing activity buffer, enzyme and substrate, and an organic 
a

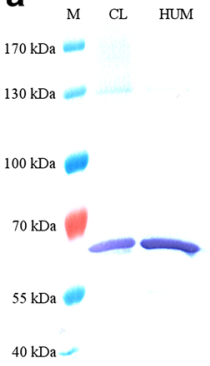

b

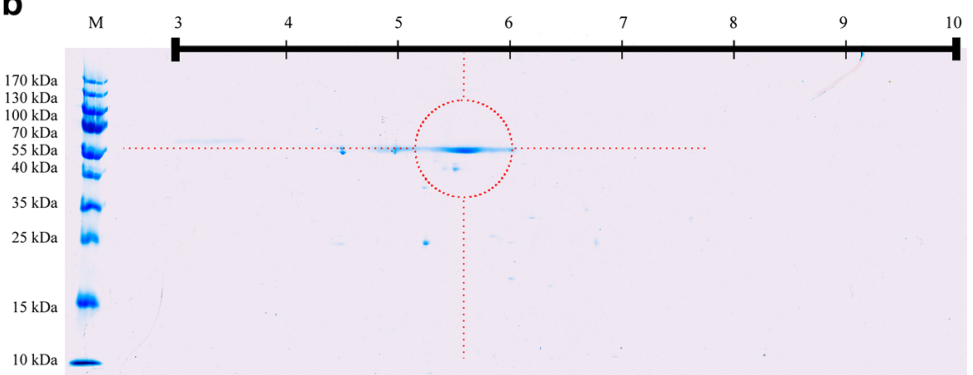

Fig. 9 Western blot of cell lysate of E. coli BL21(DE3)/pET16b::his-FXa-hum and purified HUM (a). 2D gel electrophoresis of purified HUM (b)

solvent overlay of $200 \mu \mathrm{l}$ iso-octane. Reactions were terminated by vigorous shaking, resulting in enzyme degradation and product extraction to the organic phase. The organic phase was separated and analyzed by GC-FID.

Chromatograms showed two product peaks with a ratio of $\sim 94.5: 5.5 \%$ (Fig. 10). By comparison to commercially available standards, the major product could be identified as $\alpha$ humulene and the minor product of the recombinant enzyme as $\beta$-caryophyllene.

Characterization of enzyme activity in dependence of temperature and $\mathrm{pH}$ was carried out by analyzing reaction rates at various temperatures $\left(34-44^{\circ} \mathrm{C}\right)$ and $\mathrm{pH}(\mathrm{pH}$ 6-9) (Fig. 11a, b). Reactions were carried out in the aforementioned two-phase system. Studies of the recombinant terpene synthase showed an optimal activity at $38{ }^{\circ} \mathrm{C}$. Testing the synthase activity at different $\mathrm{pH}$ showed optimum activity at $\mathrm{pH}$ 7.5. In previously published data, temperature and $\mathrm{pH}$ optimum for sesquiterpene synthases are reported to lie in a range of $20-40{ }^{\circ} \mathrm{C}[25]$ and $\mathrm{pH}$ 6.0-7.0, respectively [26], which is consistent with the results obtained in this work.

Kinetic properties were measured using FDP as a substrate with above determined optimal reaction conditions in a range of 1 to $100 \mu \mathrm{M}$. Measuring of product concentrations trapped in the organic layer was done by peak integration using GC-FID, based on an $\alpha$-humulene calibration curve. An enzyme concentration of $0.05 \mu \mathrm{M}$ was found to be suitable in preliminary tests to obtain initial reaction rates in a linear range. The data were fitted to an assumed Michaelis-Menten model using non-linear curve fitting (Fig. 12).

Michaelis-Menten constant $K_{\mathrm{M}}$ and maximum reaction rate $v_{\max }$ were calculated for $\alpha$ humulene as a single product $\left(K_{\mathrm{M}}=33.07 \mu \mathrm{M}, \mathrm{v}_{\max }=0.19 \mu \mathrm{M} \cdot \mathrm{s}^{-1}, k_{\mathrm{cat}}=3.80 \mathrm{~s}^{-1}\right)$ and the total product spectrum $\left(K_{\mathrm{M}}=32.79 \mu \mathrm{M}, v_{\max }=0.20 \mu \mathrm{M} \cdot \mathrm{s}^{-1}, k_{\mathrm{cat}}=3.91 \mathrm{~s}^{-1}\right)$. The relatively low $K_{\mathrm{M}}$ value signifies a high binding affinity of HUM to its substrate FDP. In comparison to other sesquiterpene synthases, the Michaelis-Menten constant of HUM mostly ranks higher, e.g., the sesquiterpene

Fig. 10 GC-FID chromatogram showing analyzed organic phase with conversion products $\alpha$-humulene (1) and $\beta$-caryophyllene (2) of recombinant HUM

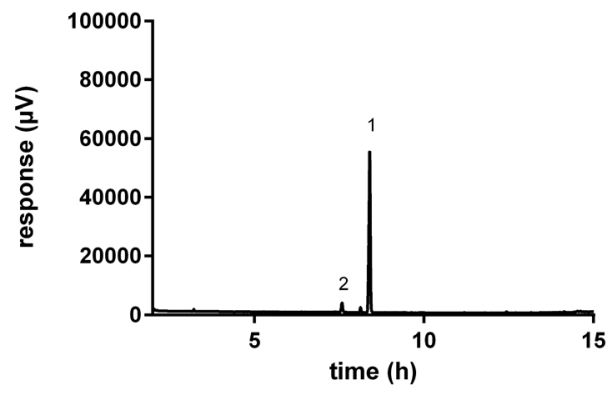


Fig. 11 Relative activity of recombinant HUM in dependence of $\mathrm{pH}$ (a) and temperature (b). Initial rate of reaction was plotted against increasing $\mathrm{pH}$ and temperature, respectively. Each data point represents at least two individual linear regression plots with product concentrations determined at five time points
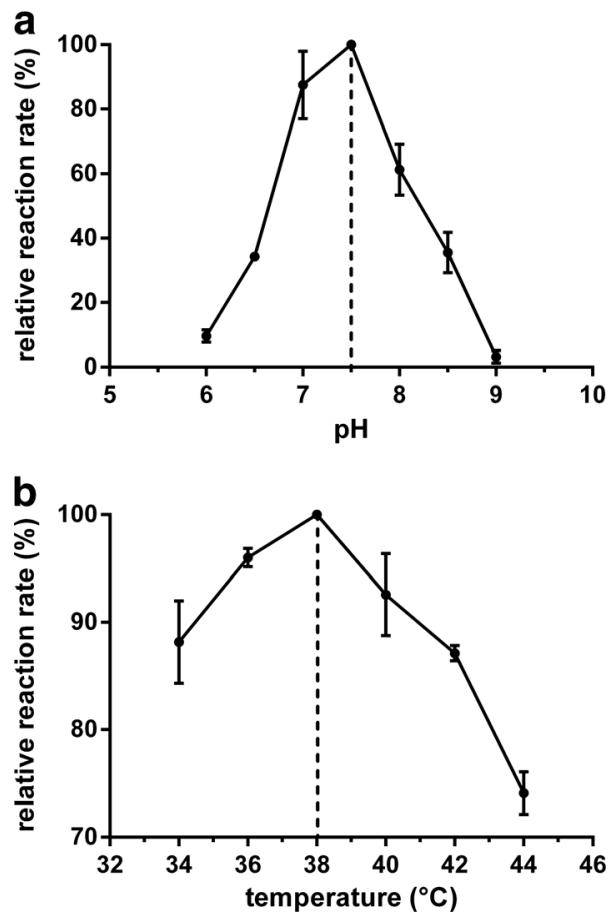

synthase (+)-germacrene D synthase $\left(K_{\mathrm{M}}=2.5 \mu \mathrm{M}\right)$ [27] which shows a high sequence similarity (identity $>63 \%$ ) has a $K_{\mathrm{M}}$ value that is about 13 times lower. However, it is reported that enzymes binding to substrates with a molecular weight above $350 \mathrm{~g} \cdot \mathrm{mol}^{-1}$ show an average $K_{\mathrm{M}}$ value of approximately $40 \mu \mathrm{M}$ [28]. Also, similar $K_{\mathrm{M}}$ values are observed within the whole class of terpene synthases $[29,30]$. The maximum reaction rate $v_{\max } 0.20 \mu \mathrm{M} \cdot \mathrm{s}^{-1}$ and the derived turnover number $k_{\text {cat }} 3.91 \mathrm{~s}^{-1}$ are rather high compared to many other described sesquiterpene synthases. Considering the relatively simple reaction catalyzed (just one cyclization reaction) compared to terpene synthases with a broad or complex product spectrum $[25,31]$, this result could be explainable. Also, the turnover number of the HUM lies in the typical range of enzymes of the secondary metabolism [25] and is not uncommon between sesquiterpene synthases [32, 33].

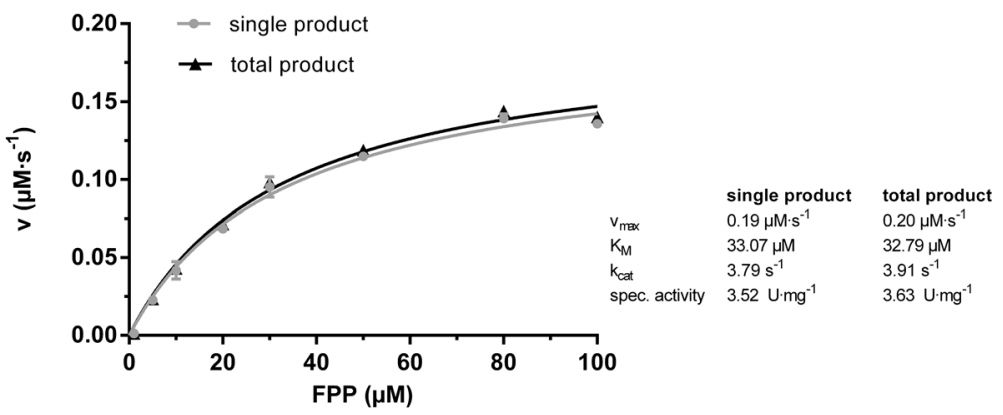

Fig. 12 Michaelis-Menten fitted plot. Initial rate of reaction was plotted against increasing substrate concentrations. Each data point represents at least two individual linear regression plots with product concentrations determined at five time points 


\section{Conclusion}

We have successfully expressed, purified, and biochemically characterized the sesquiterpene synthase $\alpha$-humulene synthase from shampoo ginger (Z. zerumbet Smith) for the biocatalytic production of $\alpha$-humulene. This is the first time to report the key enzymatic properties of $\alpha$ humulene synthase. Since the synthesis of the macrocyclic sesquiterpene $\alpha$-humulene is chemically challenging, bioconversion strategies can provide an efficient route for large scale production of sesquiterpenes. Further studies will aim at converting the major product $\alpha$ humulene in vitro to the valuable sesquiterpenoid zerumbone.

Acknowledgments This study was funded by the European Regional Development Fund (EFRE): Innovation Network "Refinement of plant resources" (ZW-8-80130940).

\section{Compliance with Ethical Standards}

Conflict of Interest The authors declare that they have no competing interests.

\section{References}

1. Webster, N. S., Wilson, K. J., Blackall, L. L., \& Hill, R. T. (2001). Phylogenetic diversity of bacteria associated with the marine sponge Rhopaloeides odorabile. Applied Environmental Microbiology, 67, 434-444.

2. Lam, K. S. (2006). Discovery of novel metabolites from marine actinomycetes. Current Opinion in Microbiology, 9, 245-251.

3. Kingston, D. G. I. (2011). Modern natural products drug discovery and its relevance to biodiversity conservation. Journal of Natural Products, 74, 496-511.

4. Trapp, S. C., \& Croteau, R. B. (2001). Genomic organization of plant terpene synthases and molecular evolutionary implications. Genetics, $158,811-832$.

5. Chen, F., Tholl, D., Bohlmann, J., \& Pichersky, E. (2011). The family of terpene synthases in plants: a midsize family of genes for specialized metabolism that is highly diversified throughout the kingdom. The Plant Journal, 66, 212-229.

6. McGarvey, D. J., \& Croteau, R. B. (1995). Terpenoid metabolism. The Plant Cell, 7, 1015-1026.

7. Peters, R. J. (2013). In T. J. Bach \& M. Rohmer (Eds.), Isoprenoid synthesis in plants and microorganisms: gibberellin phytohormone metabolism (pp. 233-249). NY: Springer.

8. Unsicker, S. B., Kunert, G., \& Gershenzon, J. (2009). Protective perfumes: the role of vegetative volatiles in plant defense against herbivores. Current Opinion in Plant Biology, 12, 479-485.

9. Arimura, G., Ozawa, R., Nishioka, T., Boland, W., Koch, T., Kühnemann, F., \& Takabayashi, J. (2002). Herbivory-induced leaf volatiles trigger JA-and/or ethylene-dependent activation of ethylene biosynthesis genes in uninfested leaves. The Plant Journal, 29, 87-98.

10. Wang, G., Tang, W., \& Bidigare, R. R. (2005). In L. Zhang \& A. L. Demain (Eds.), Natural products: drug discovery and therapeutic medicine: terpenoids as therapeutic drugs and pharmaceutical agents (pp. 197227). Totowa, NJ: Humana Press.

11. Yu, F., Okamto, S., Nakasone, K., Adachi, K., Matsuda, S., Harada, H., Misawa, N., \& Utsumi, R. (2008). Molecular cloning and functional characterization of $\alpha$-humulene synthase, a possible key enzyme of zerumbone biosynthesis in shampoo ginger (Zingiber zerumbet Smith). Planta, 227, 1291-1299.

12. Kader, G., Nikkon, F., Rashid, M. A., \& Yeasmin, T. (2011). Antimicrobial activities of the rhizome extract of Zingiber zerumbet Linn. Asian Pacific Journal of Tropical Biomedicine, 1, 409-412.

13. Habsah, M., Amran, M., Mackeen, M. M., Lajis, N. H., Kikuzaki, H., Nakatani, N., Rahman, A., Ghafar, A., \& Ali, A. M. (2000). Screening of Zingiberaceae extracts for antimicrobial and antioxidant activities. Journal of Ethnopharmacology, 72, 403-410.

14. Tzeng, T.F., Liou, S.S., Chang, C.J. and Liu, I.M. (2013) The Ethanol Extract of Zingiber zerumbet Attenuates Streptozotocin-Induced Diabetic Nephropathy in Rats. Evidence-Based Complementary and Alternative Medicine. Article ID 340645, 8 pages 
15. Wahab, S. I. A., Abdul, A. B., Yeel, H. C., Alzubain, A. S., Elhassan, M. M., \& Syam, M. M. (2008). Antitumor activities of analogues derived from the bioactive compound of Zingiber zerumbet. International Journal Of Cancer Research, 4, 154-159.

16. Murakami, A., Miyamoto, M., \& Ohigashi, H. (2004). Zerumbone, an anti-inflammatory phytochemical, induces expression of proinflammatory cytokine genes in human colon adenocarcinoma cell lines. BioFactors, 21, 95-101.

17. Shamoto, T., Matsuo, Y., \& Shibata, T. (2014). Zerumbone inhibits angiogenesis by blocking NF-kB activity in pancreatic cancer. Pancreas, 43, 396-404.

18. Tewtrakul, S., \& Subhadhirasakul, S. (2007). Anti-allergic activity of some selected plants in the Zingiberaceae family. Journal of Ethnopharmacology, 109, 535-538.

19. Croteau, R. B., Davis, E. M., Ringer, K. L., \& Wildung, M. R. (2005). (-)-Menthol biosynthesis and molecular genetics. Naturwissenschaften, 92, 562-577.

20. Gershenzon, J., Maffei, M., \& Croteau, R. B. (1989). Biochemical and histochemical localization of monoterpene biosynthesis in the glandular trichomes of spearmint (Mentha spicata). Plant Physiology, 89, 1351-1357.

21. Yu, F., Okamoto, S., Harada, H., Yamasaki, K., Misawa, N., \& Utsumi, R. (2011). Zingiber zerumbet CYP71BA1 catalyzes the conversion of alpha-humulene to 8-hydroxy-alpha-humulene in zerumbone biosynthesis. Cellular and Molecular Life Sciences, 68, 1033-1040.

22. Okamoto, S., Yu, F., Harada, H., Okajima, T., Hattan, J. I., Misawa, N., \& Utsumi, R. (2011). A short-chain dehydrogenase involved in terpene metabolism from Zingiber zerumbet. FEBS Journal, 27, 2892-2900.

23. Puigbò, P., Guzmán, E., Romeu, A., \& Garcia-Vallvé, S. (2007). OPTIMIZER: a web server for optimizing the codon usage of DNA sequences. Nucleic Acids Research, 35, W126-W131.

24. Eriksen, N. T., Kratchmarova, I., Neve, S., Kristiansen, K., \& Iversen, J. J. L. (2001). Automatic inducer addition and harvesting of recombinant Escherichia coli cultures based on indirect on-line estimation of biomass concentration and specific growth rate. Biotechnology and Bioengineering, 75, 335-361.

25. Hartwig, S., Frister, T., Alemdar, S., Li, Z., Scheper, T., \& Beutel, S. (2015). SUMO-fusion, purification, and characterization of a (+)-zizaene synthase from Chrysopogon zizanioides. Biochemical and Biophysical Research Communications, 458, 883-889.

26. Frister, T., Hartwig, S., Alemdar, S., Schnatz, K., Thöns, L., Scheper, T., \& Beutel, S. (2015). Characterisation of a recombinant patchoulol synthase variant for biocatalytic production of terpenes. Applied Biochemistry and Biotechnology, 176, 2185-2201.

27. Mercke, P., Bengtsson, M., Bouwmeester, H. J., Posthumus, M. A., \& Brodelius, P. E. (2000). Molecular cloning, expression, and characterization of amorpha-4,11-diene synthase, a key enzyme of artemisinin biosynthesis in Artemisia annua L. Archives of Biochemistry and Biophysics, 381, 173.

28. Nieuwenhuizen, N. J., Wang, M. Y., Matich, A. J., Green, S. A., Chen, X., Yauk, Y. K., Beuning, L. L., Nagegowda, D. A., Dudareva, N., \& Atkinson, R. G. (2009). Two terpene synthases are responsible for the major sesquiterpenes emitted from the flowers of kiwifruit (Actinidia deliciosa). Journal of Experimental Botany, 60, 3203-3219.

29. Bar-Even, A., Noor, E., Savir, Y., Liebermeister, W., Davidi, D., Tawfik, D. S., \& Milo, R. (2011). The moderately efficient enzyme: evolutionary and physico-chemical trends shaping enzyme kinetics. Biochemistry, 50, 4402-4410.

30. Crowell, A. L., Williams, D. C., Davis, E. M., Wildung, M. R., \& Croteau, R. (2002). Molecular cloning and characterization of a new linalool synthase. Archives of Biochemistry and Biophysics, 405, 112-121.

31. Faraldos, J. A., Gonzalez, V., Li, A., Yu, F., Koeksal, M., Christianson, D. W., \& Allemann, R. K. (2012). Probing the mechanism of 1,4-conjugate elimination reactions catalyzed by terpene synthases. Journal of the American Chemical Society, 134, 20844-20848.

32. Agger, S. A., Lopez-Gallego, F., Hoye, T. R., \& Schmidt-Dannert, C. (2008). Identification of sesquiterpene synthases from Nostoc punctiforme PCC 73102 and Nostoc sp. strain PCC 7120. Journal of Bacteriology, 190, 6084-6096.

33. Pinedo, C., Wang, C., Pradier, J., Dalmais, B., Choquer, M., Le, P. P., Morgant, G., Collado, I. G., Cane, D. E., \& Viaud, M. (2008). Sesquiterpene synthase from the botrydial biosynthetic gene cluster of the phytopathogen Botrytis cinerea. ACS Chemical Biology, 3, 791-801. 